\title{
Silica Sulfuric Acid: An Eco-Friendly and Reusable Catalyst for Synthesis of Benzimidazole Derivatives
}

\author{
Bahareh Sadeghi and Mahboobeh Ghasemi Nejad \\ Department of Chemistry, Islamic Azad University, Yazd Branch, P.O. Box 89195-155, Yazd, Iran \\ Correspondence should be addressed to Bahareh Sadeghi; bsadeghia@gmail.com
}

Received 7 February 2012; Accepted 14 June 2012

Academic Editor: Christophe Len

Copyright (C) 2013 B. Sadeghi and M. Ghasemi Nejad. This is an open access article distributed under the Creative Commons Attribution License, which permits unrestricted use, distribution, and reproduction in any medium, provided the original work is properly cited.

\begin{abstract}
Silica sulfuric acid $\left(\mathrm{SiO}_{2}-\mathrm{OSO}_{3} \mathrm{H}\right)$ as an eco-friendly, readily available, and reusable catalyst is applied to benzimidazole derivatives synthesis under reflux in ethanol. The procedure is very simple and the products are isolated with an easy workup in good-toexcellent yields.
\end{abstract}

\section{Introduction}

Benzimidazole derivatives are found in many biologically active compounds possessing antiviral, antihypertension, and anticancer properties [1, 2]. Compounds possessing the benzimidazole moiety exhibit significant activity against several viruses such as HIV [3, 4], herpes (HSV-1) [5], RNA [6], influenza [7], and human cytomegalovirus (HCMV) [3, 4]. Specifically, the 2-substituted analogs of benzimidazoles are known to be potent biologically active compounds [8]. There are several methods for benzimidazole synthesis; these compounds are conventionally prepared using condensation of $o$-phenylenediamine with carbonyl compounds in the presence of strong acids such as $\mathrm{Me}_{2} \mathrm{~S}^{+} \mathrm{BrBr}^{-7}$, $\mathrm{P}-\mathrm{TsOH}$ [9], Alumina-methanesulfnic acid [10], $\mathrm{BF}_{3} \cdot \mathrm{OEt}_{2}$ [11], ceric(IV) ammonium nitrate [12]. However, many of the synthetic protocols reported so far suffer from disadvantages, such as a requirement for anhydrous conditions, use of organic solvents, harsh reaction conditions, expensive reagents, and low-to-moderate yields. Therefore, the development of a simple, mild, and efficient method is still needed.

Solid supported reagents have improved activity and selectivity than individual reagents, because the surface area of the reagent is increased manifold [14].

Silica sulfuric acid $\left(\mathrm{SiO}_{2}-\mathrm{OSO}_{3} \mathrm{H}\right)$, a solid acid, is a versatile catalyst that makes reaction processes more convenient, more economic, and environmentally benign. Owing to the numerous advantages associated with this cheap and nonhazardous catalyst, under mild conditions, silica sulfuric acid has been explored as a powerful catalyst for various organic transformations $[15,16]$. This solid acid has also been used in synthesis of oxazolines and imidazolines [17], synthesis of 2,3-dihydroquinazolin-4(1H)-ones [18], synthesis of substituted pyrroles [19], chemoselective detritylation of $5^{\prime}$-tritylated nucleosides [20], and deprotection of oxime to carbonyls [21]. In this paper, we wish to report an efficient and versatile procedure for the synthesis of 2-substituted benzimidazole derivatives in the presence of silica sulfuric acid.

We now wish to describe our efforts towards the synthesis of 2-substituted benzimidazole derivatives in the prescence of solid acid catalyst see Scheme 1.

\section{Experimental}

The products were known and were characterized by IR and NMR and by comparing their physical properties with those reported in the literature. IR spectra were run on a Shimadzu IR-470 spectrometer. NMR was obtained using a Bruker Avans $400 \mathrm{MHz}$ spectrometer. Melting points were determined with a Barnstead Electrothermal melting point apparatus. Elemental analyses were performed using a Costech ECS 4010 CHNS-O analyzer. 
TABLE 1: Acid-catalyzed synthesis of 2-(phenyl)benzimidazole.

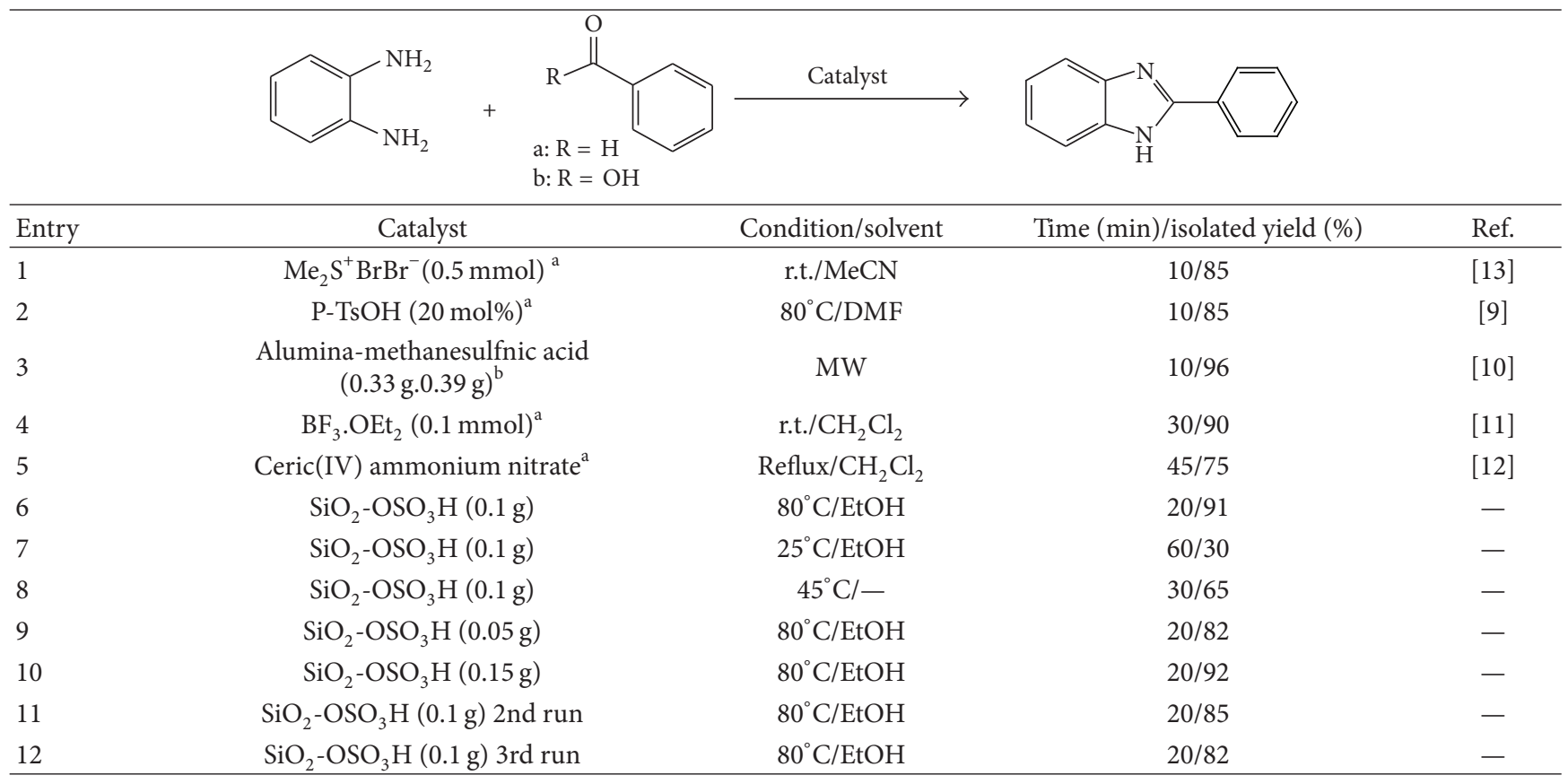

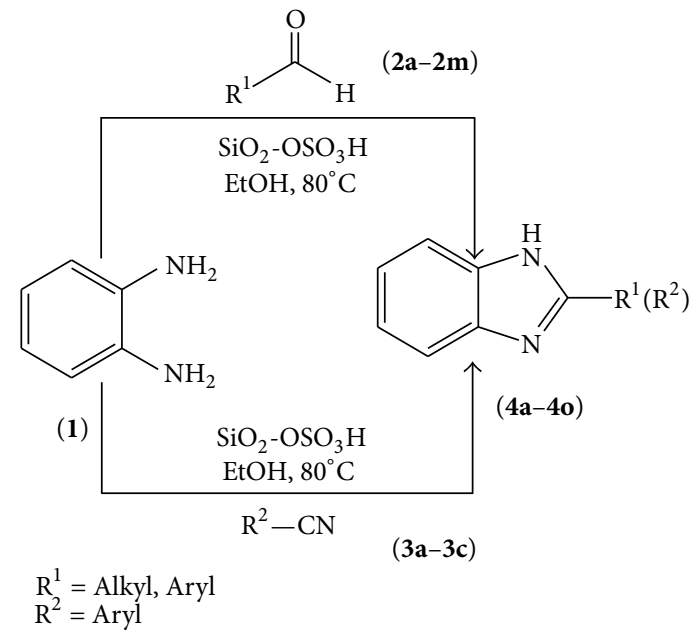

SCHeme 1: Synthesis of benzimidazoles (4) using aldehydes (2) or benzonitriles (3) and $o$-phenylenediamine (1) in the presence of $\mathrm{SiO}_{2}-\mathrm{OSO}_{3} \mathrm{H}$.

Benzonitrile or aldehyde ( $1 \mathrm{mmol}), o$-phenylenediamine $(1 \mathrm{mmol})$, and ethanol in the presence of $\mathrm{SiO}_{2}-\mathrm{OSO}_{3} \mathrm{H}(0.1 \mathrm{~g})$ were placed in a round bottom flask. The materials were mixed and heated at reflux for $20 \mathrm{~min}$. The progress of the reaction was followed by TLC ( $3: 1: n$-hexane:ethylacetate). After the completion of the reaction, the mixture was filtered to remove the catalyst. By evaporation of the solvent, the crude product was recrystallized from hot aq. ethanol to obtain the pure compound. All products are known and were identified by comparison of their physical or spectral data with those of authentic samples.

\section{Results and Discussion}

In continuation of our investigation about application of solid acids in organic synthesis [22, 23], we herein report a simple and efficient protocol for benzimidazole synthesis using a cheap and readily available $\mathrm{SiO}_{2}-\mathrm{OSO}_{3} \mathrm{H}$ catalyst. The efficiency of this acid is comparable with some other catalysts such as $\mathrm{Me}_{2} \mathrm{~S}^{+} \mathrm{BrBr}^{-}$, $\mathrm{P}-\mathrm{TsOH}$, alumina-methanesulfunic acid, and $\mathrm{BF}_{3} \cdot \mathrm{OEt}_{2}$. Most of these methods have limitations such as organic solvents, fuming catalyst, and harsh reaction condition. To optimize the catalytic system, the synthesis of 2-(phenyl)benzimidazole was used as a model reaction. The catalytic activity and efficiency of this method can be influenced by various parameters such as the employed catalyst, catalyst amount, and temperature.

Silica sulfuric acid, owing to the numerous advantages such as solid acid, nonhazardous, and available was selected for this protocol.

It is worthwhile to mention that the minimum amount of the catalyst was optimized to be $0.1 \mathrm{~g}$.

The effect of temperature was studied by carrying out the model reaction in the presence of silica sulfuric acid $(0.1 \mathrm{~g})$ in ethanol $(10 \mathrm{~mL})$ and solvent-free at different temperatures (room temperature, 45 and $80^{\circ} \mathrm{C}$ ). It was observed (Table 1 , entries 6,7 , and 8 ) that the yield was increased as the reaction temperature was raised. From these results, $80^{\circ} \mathrm{C}$ is selected as the best temperature for all future studies.

The reusability of the $\mathrm{SiO}_{2}-\mathrm{OSO}_{3} \mathrm{H}$ catalyst was also examined. After each run, $\mathrm{CHCl}_{3}$ was added and the product was filtered, the solvent evaporated and the residue (catalyst) was washed with $\mathrm{CHCl}_{3}$ and reused. Apparently, treatment with $\mathrm{CHCl}_{3}$ removes tars more efficiently from the catalyst surface (Table 1, entries 11 and 12). This catalyst was reusable, although a gradual decline in activity was observed. 
TABLE 2: Synthesis of benzimidazoles catalyzed by silica sulfuric acid ${ }^{\mathrm{a}}$.

\begin{tabular}{|c|c|c|c|c|c|c|}
\hline Entry & $R^{1}$ & $R^{2}$ & Product $^{\mathrm{b}}$ & Yield $/ \%^{\mathrm{c}}$ & M.P. $/^{\circ} \mathrm{C}$ & Ref. \\
\hline 1 & $\begin{array}{l}\mathrm{C}_{6} \mathrm{H}_{5} \\
\mathbf{2 a}\end{array}$ & - & & 91 & 289-291 & [9] \\
\hline 2 & $\begin{array}{c}4-\mathrm{ClC}_{6} \mathrm{H}_{4} \\
\mathbf{2 b}\end{array}$ & - & & 87 & $288-291$ & [9] \\
\hline 3 & $\begin{array}{c}2-\mathrm{ClC}_{6} \mathrm{H}_{4} \\
2 \mathrm{c}\end{array}$ & - & & 89 & $230-231$ & [9] \\
\hline 4 & $\begin{array}{c}4-\mathrm{CH}_{3} \mathrm{C}_{6} \mathrm{H}_{4} \\
\mathbf{2 d}\end{array}$ & - & & 82 & $262-264$ & [9] \\
\hline 5 & $\underset{2 \mathrm{e}}{2-\mathrm{OMeC}_{6} \mathrm{H}_{4}}$ & - & & 84 & $224-227$ & {$[10]$} \\
\hline 6 & $\begin{array}{c}3,4-\mathrm{OMeC}_{6} \mathrm{H}_{3} \\
\mathbf{2 f}\end{array}$ & - & & 80 & $228-230$ & [13] \\
\hline 7 & $\begin{array}{c}3-\mathrm{NO}_{2} \mathrm{C}_{6} \mathrm{H}_{4} \\
\mathbf{2 g}\end{array}$ & - & & 85 & $202-204$ & [9] \\
\hline 8 & $\underset{\mathbf{2 h}}{4-\mathrm{NO}_{2} \mathrm{C}_{6} \mathrm{H}_{4}}$ & - & & 86 & $308-310$ & [9] \\
\hline 9 & $\begin{array}{c}\mathrm{CH}_{3} \mathrm{CH}_{2} \\
\mathbf{2 i}\end{array}$ & - & & 74 & $172-174$ & {$[10]$} \\
\hline 10 & $\begin{array}{c}4-\mathrm{OMeC}_{6} \mathrm{H}_{4} \\
\mathbf{2 j}\end{array}$ & - & & 89 & $224-226$ & [12] \\
\hline 11 & $\begin{array}{c}\mathrm{C}_{6} \mathrm{H}_{5} \mathrm{CH}=\mathrm{CH} \\
\mathbf{2 k}\end{array}$ & - & & 90 & 199-202 & [11] \\
\hline 12 & $\begin{array}{c}\mathrm{C}_{4} \mathrm{H}_{3} \mathrm{~S} \\
21\end{array}$ & - & & 78 & $327-329$ & [12] \\
\hline 13 & $\begin{array}{c}\mathrm{C}_{5} \mathrm{H}_{4} \mathrm{~N} \\
\mathbf{2} \mathbf{m}\end{array}$ & - & & 81 & $218-220$ & [12] \\
\hline 14 & - & $\begin{array}{c}4-\mathrm{BrC}_{6} \mathrm{H}_{4} \\
\mathbf{3 a}\end{array}$ & & 86 & $283-285$ & {$[10]$} \\
\hline
\end{tabular}


TABLE 2: Continued.

\begin{tabular}{|c|c|c|c|c|c|c|}
\hline Entry & $R^{1}$ & $R^{2}$ & Product $^{\mathrm{b}}$ & Yield $/ \%^{\mathrm{c}}$ & M.P. ${ }^{\circ} \mathrm{C}$ & Ref. \\
\hline 15 & - & $\begin{array}{c}\mathrm{C}_{6} \mathrm{H}_{5} \\
\mathbf{3 b}\end{array}$ & & 85 & 289-291 & [9] \\
\hline 16 & - & $\begin{array}{c}4-\mathrm{NH}_{2} \mathrm{C}_{6} \mathrm{H}_{4} \\
3 \mathrm{c}\end{array}$ & & 82 & $202-204$ & {$[10]$} \\
\hline
\end{tabular}

Molar ratio of aldehyde or benzonitrile: 2 -amino aniline: $\mathrm{SiO}_{2}-\mathrm{OSO}_{3} \mathrm{H}(\mathrm{g})$ was $1: 1: 0.1$. ${ }^{\mathrm{b}}$ Isolated yield. ${ }^{\mathrm{c}}$ All products are known and were identified by their melting points, IR, ${ }^{1} \mathrm{H}$ NMR, and ${ }^{13} \mathrm{C}$ NMR spectra.

We also tried to use benzonitrile instead of benzaldehyde in the model reaction (Table 2, entry 15). We can mention fortunately, that our attempts to carry out the reaction in the presence of benzonitrile were successful.

To show the generality of this method, the optimized conditions used for the synthesis of other benzimidazoles and all results are summarized in Table 2. As shown in Table 2, this method is effective for the preparation of benzimidazoles from both benzonitrile derivatives as well as benzaldehydes.

The work-up procedure of this reaction is very simple. After completion of reaction the mixture was filtered off to separate the catalyst and then the solvent was evaporated to dryness under reduced pressure. The pure products were obtained by recrystallization from a mixture of ethanol and water.

\section{Conclusion}

In summary, silica sulfuric acid is an efficient catalyst for the synthesis of benzimidazoles. In addition, as a water stable solid acid, reusable, and green catalyst, the handling of this catalyst is easy, it makes this catalyst suitable for the largescale operation. The reaction appears to be heterogeneously catalyzed. High yields, relatively short reaction times, simplicity of operation, and easy work-up procedure are some other advantages of this protocol.

\section{Acknowledgment}

The author thanks the Islamic Azad University of Yazd for financial support of this paper.

\section{References}

[1] D. A. Horton, G. T. Bourne, and M. L. Sinythe, "The combinatorial synthesis of bicyclic privileged structures or privileged substructures," ChemicalReviews, vol. 103, no. 3, pp. 893-930, 2003.

[2] M. Alamgir, C. D. Black, and N. Top Kumar, "Synthesis, reactivity and biological activity of benzimidazoles," Heterocyclic Chemistry, vol. 9, pp. 87-118, 2007.

[3] A. R. Porcari, R. V. Devivar, L. S. Kucera, J. C. Drach, and L. B. Townsend, "Design, synthesis, and antiviral evaluations of 1-(substituted benzyl)- 2-substituted-5,6-dichlorobenzimidazoles as nonnucleoside analogues of 2,5,6- trichloro-1-( $\beta$-Dribofuranosyl)benzimidazole," Journal of Medicinal Chemistry, vol. 41, no. 8, pp. 1252-1262, 1998.

[4] T. Roth, M. L. Morningstar, P. L. Boyer, S. H. Hughes, R. W. Buckheit, and C. J. Michejda, "Synthesis and biological activity of novel nonnucleoside inhibitors of HIV-1 reverse transcriptase. 2-Aryl-substituted benzimidazoles," Journal of Medicinal Chemistry, vol. 40, no. 26, pp. 4199-4207, 1997.

[5] M. T. Migawa, J. L. Girardet, J. A. Walker et al., "Design, synthesis, and antiviral activity of $\alpha$-nucleosides: $\mathrm{D}$ - and L- isomers of lyxofuranosyl- and (5-deoxylyxofuranosyl)benzimidazoles," Journal of Medicinal Chemistry, vol. 41, no. 8, pp. 1242-1251, 1998.

[6] I. Tamm and P. B. Sehgal, "Halobenzimidazole ribosides and RNA synthesis of cells and viruses," Advances in Virus Research, vol. 22, pp. 187-258, 1978.

[7] I. Tamm, "Inhibition of influenza and mumps virus multiplication by 4,5,6- (or 5,6,7-) trichloro-1- $\beta$-D-ribofuranosylbenzimidazole," Science, vol. 120, no. 3125, pp. 847-848, 1954.

[8] Z. Kazimierczuk, M. Andrzejewska, J. Kaustova, and V. Klimesova, "Synthesis and antimycobacterial activity of 2substituted halogenobenzimidazoles," European Journal of Medicinal Chemistry, vol. 40, no. 2, pp. 203-208, 2005.

[9] H. Xiangming, M. Huiqiang, and W. Yulu, "p-TsOH catalyzed synthesis of 2-arylsubstituted benzimidazoles," Arkivoc, vol. 2007, no. 13, pp. 150-154, 2007.

[10] K. Niknam and A. Fatehi-Raviz, "Synthesis of 2-substituted benzimidazoles and bis-benzimidazoles by microwave in the presence of alumina-methanesulfonic acid," Journal of the Iranian Chemical Society, vol. 4, no. 4, pp. 438-443, 2007.

[11] R. R. Nagawade and D. B. Shinde, " $\mathrm{BF}_{3} \mathrm{OET}_{2}$ promoted solvent free synthesis of benzimidazole derivatives," Chinese Chemical Letters, vol. 17, no. 4, pp. 453-456, 2006.

[12] R. Kumar and Y. C. Joshi, "Mild and efficient one pot synthesis of imidazolinesand benzimidazoles from aldehydes," E-Journal of Chemistry, vol. 4, no. 4, pp. 606-610, 2007.

[13] B. Das, H. Holla, and Y. Srinivas, "Efficient (bromodimethyl)sulfonium bromide mediated synthesis of benzimidazoles," Tetrahedron Letters, vol. 48, no. 1, pp. 61-64, 2007.

[14] A. Corma and H. Garcia, "Silica-bound homogenous catalysts as recoverable and reusable catalysts in organic synthesis," Advanced Synthesis \& Catalysis, vol. 348, no. 12-13, pp. 1391-1412, 2006.

[15] P. Salehi, M. A. Zolfigol, F. Shirini, and M. Baghbanzadeh, "Silica sulfuric acid and silica chloride as efficient reagents for 
organic reactions," Current Organic Chemistry, vol. 10, no. 17, pp. 2171-2189, 2006.

[16] A. Bamoniri, M. A. Zolfigoi, I. Mohammadpoor-Baltork, and B. F. Mirjalili, "The use of silica sulfuric acid as an efficient catalyst for deprotection of trimethylsilyl ethers to the corresponding alcohols under mild and heterogeneous conditions," Journal of the Iranian Chemical Society, vol. 3, no. 1, pp. 85-88, 2006.

[17] I. Mohammadpoor-Baltork, V. Mirkhani, M. Moghadam et al., "Silica sulfuric acid: a versatile and reusable heterogeneous catalyst for the synthesis of oxazolines and imidazolines under various reaction conditions," Catalysis Communications, vol. 9, no. 5, pp. 894-901, 2008.

[18] M. Dabiri, P. Salehi, M. Baghbanzadeh, M. A. Zolfigol, M. Agheb, and S. Heydari, "Silica sulfuric acid: an efficient reusable heterogeneous catalyst for the synthesis of 2,3-dihydroquinazolin-4(1H)-ones in water and under solvent-free conditions," Catalysis Communications, vol. 9, no. 5, pp. 785-788, 2008.

[19] H. Veisi, "Silica sulfuric acid (SSA) as a solid acid heterogeneous catalyst for one-pot synthesis of substituted pyrroles under solvent-free conditions at room temperature," Tetrahedron Letters, vol. 51, no. 16, pp. 2109-2114, 2010.

[20] A. Khalafi-Nezhad, A. Parhami, M. N. Soltani Rad, M. A. Zolfigol, and A. Zare, "A catalytic method for chemoselective detritylation of $5^{\prime}$-tritylated nucleosides under mild and heterogeneous conditions using silica sulfuric acid as a recyclable catalyst," Tetrahedron Letters, vol. 48, no. 30, pp. 5219-5222, 2007.

[21] J. Li, X. Meng, B. Bai, and M. Sun, "An efficient deprotection of oximes to carbonyls catalyzed by silica sulfuric acid in water under ultrasound irradiation," Ultrasonics Sonochemistry, vol. 17, no. 1, pp. 14-16, 2010.

[22] B. Sadeghi, B. F. Mirjalili, and M. M. Hashemi, " $\mathrm{SnCl}_{4} / \mathrm{SiO}_{2}$ : an efficient heterogeneous alternative for one-pot synthesis of $\beta$ acetamido ketones," Journal of the Chinese Chemical Society, vol. 56, pp. 386-391, 2009.

[23] B. Sadeghi, B. F. Mirjalili, S. Bidaki, and M. Ghasemkhani, " $\mathrm{SbCl}_{5} . \mathrm{SiO}_{2}$ : an efficient alternative for one-pot synthesis of 1,2,4,5-tetrasubstituted imidazoles in solvent or under solventfree condition," Journal of the Iranian Chemical Society, vol. 8, no. 3, pp. 648-652, 2011. 

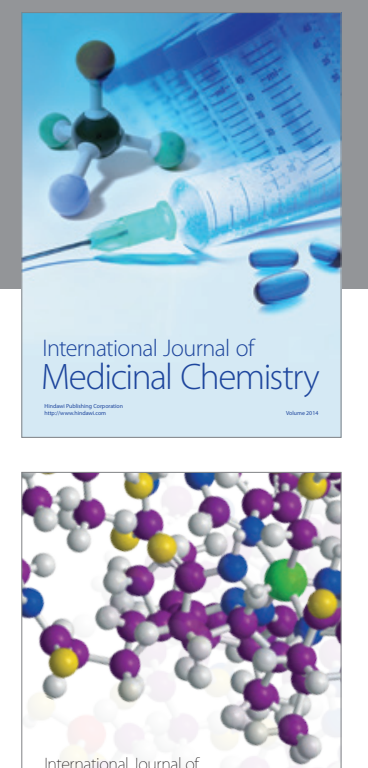

\section{Carbohydrate} Chemistry

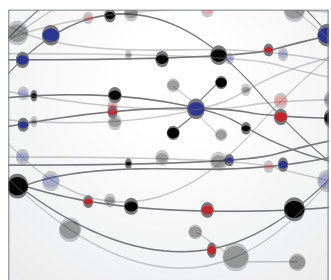

The Scientific World Journal
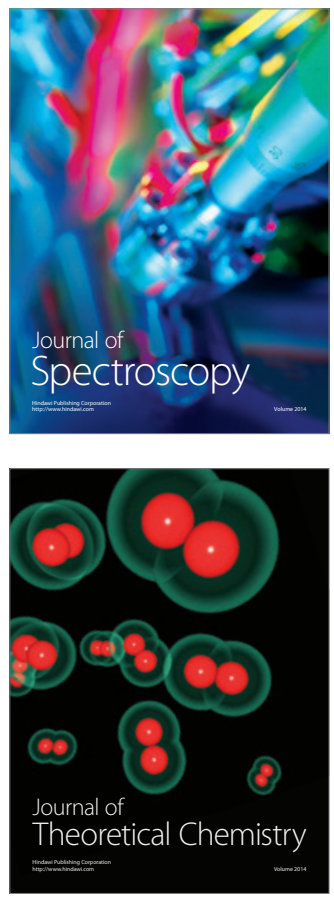
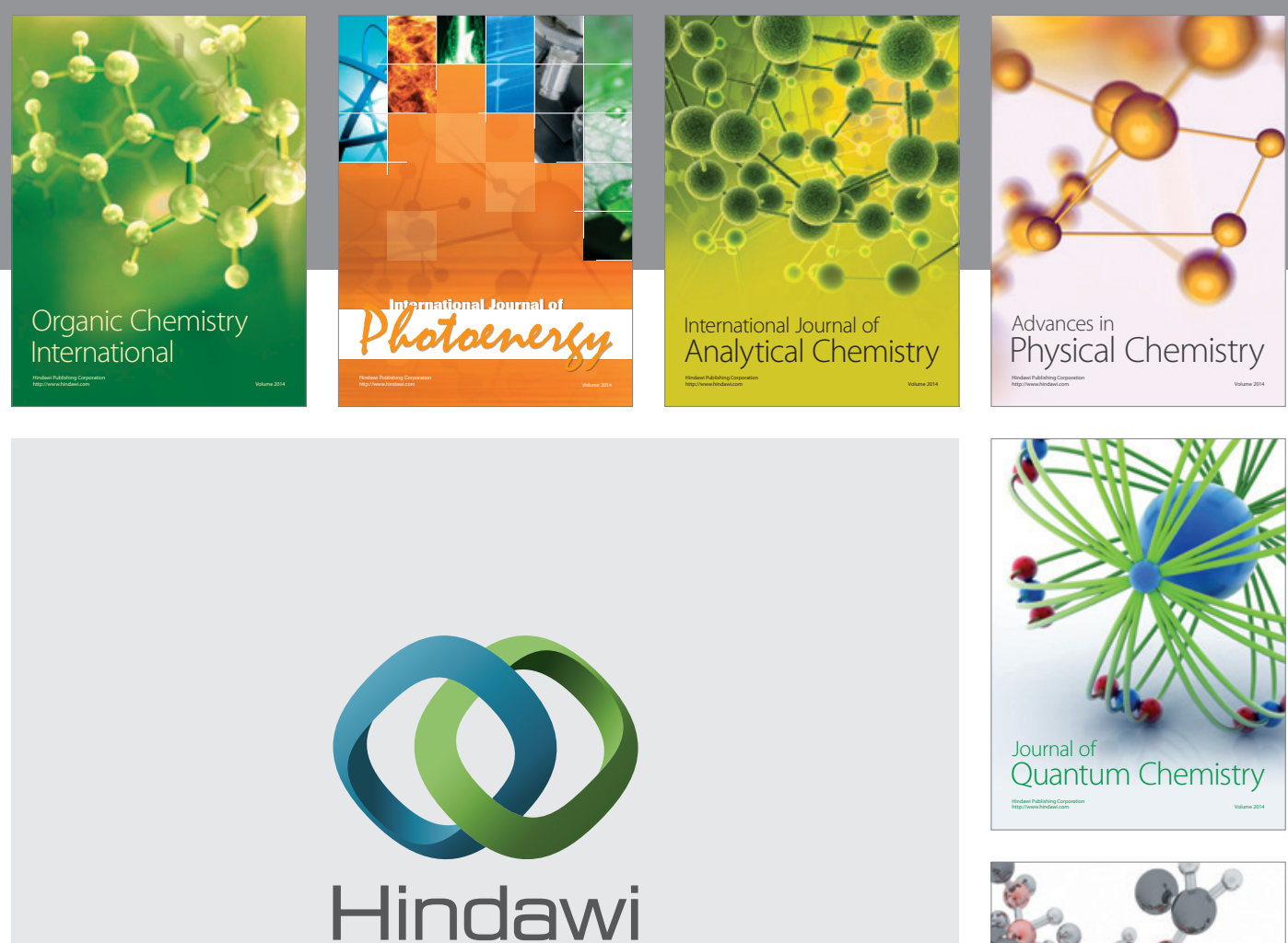

Submit your manuscripts at

http://www.hindawi.com

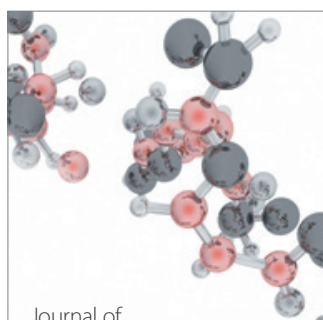

Analytical Methods

in Chemistry

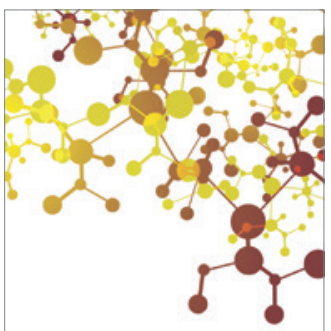

Journal of

Applied Chemistry

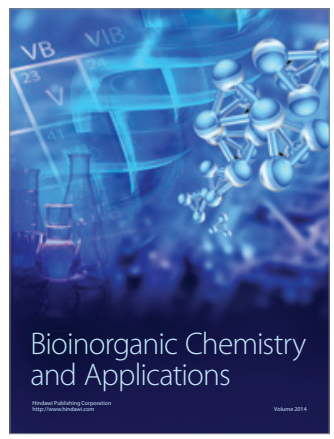

Inorganic Chemistry
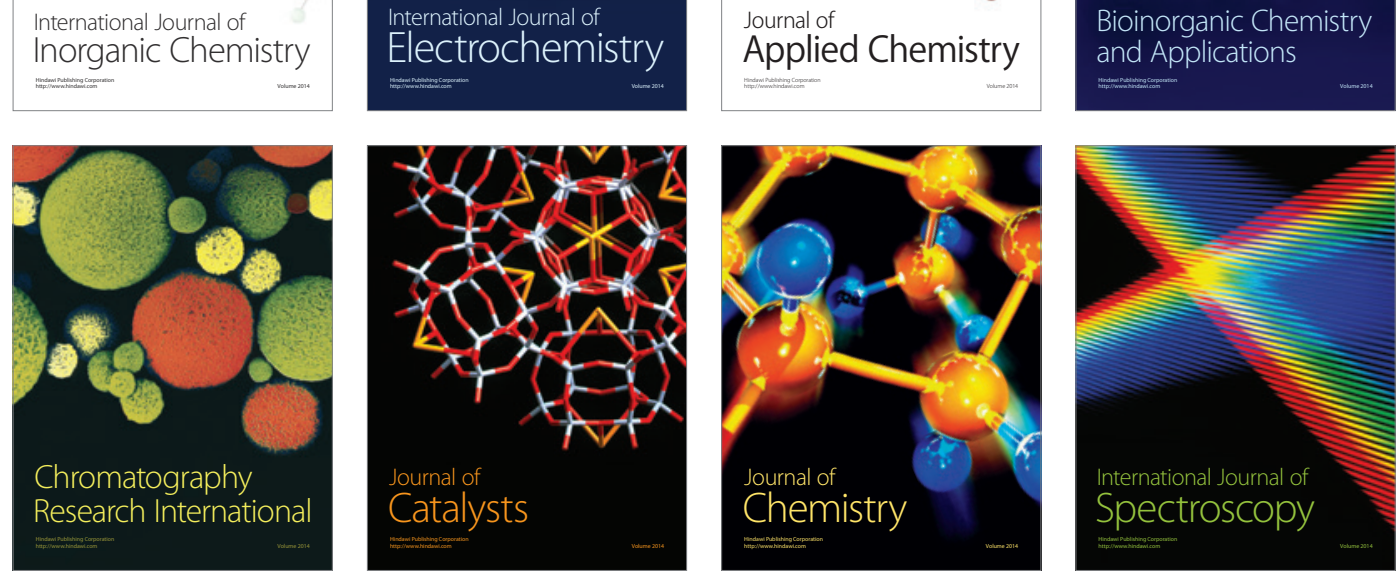